\title{
LA IDEA DEL DESARROLLO AYER Y HOY: EL DESARROLLO COMO DERECHO
}

\author{
Rolando Cordera Campos*
}

RESUMEN: La crisis de la globalidad propicia la apertura del debate sobre el desarrollo. Desde la óptica de los llamados países periféricos, el tema de la justicia social adquiere centralidad. Los estudios del desarrollo están llamados a deliberar sobre las políticas globales y el porvenir de las democracias. En esa tarea, el desarrollo se concibe como un proceso complejo que involucra grandes y pequeños cambios sociales, además de diversas formas de aprendizaje democrático. La actual coyuntura, además de poner en cuestión la conducción económica o la protección social, desafía las maneras en que las sociedades y los Estados afrontarán el actual laberinto cuya salida presagia un cambio de época. Sin embargo, la academia y los comandos políticos de la economía necesitan reflexionar en un horizonte de largo plazo para superar los tormentos actuales.

PALABRAS CLAVEः desarrollo, justicia social, globalidad, crisis, Estado.

ABSTRACT: The global crisis provides a window of oportunity for debate about development. From the perspective of the so-called periferal countries the topic of social justice is central. Development studies are called to deliberate on global politics and the coming of democracies. In this task, development is conceived as a complex process that involves large and small social changes, as well as diverse forms of democratic lessons. The current situation, besides putting in doubt economic direction or social protection, challenges the ways in which societies and the State confront today's laberynth, whose exit presages a new epoch. However, academics and political leaders of the economy need to reflect on a distant horizon in order to overcome the present storms.

KEY WORDS: development, social justice, global, crisis, State.

* Coordinador del Programa Universitario de Estudios del Desarrollo (pued) de la Universidad Nacional Autónoma de México (unam), México. 


\section{A MANERA DE INTRODUCCIÓN ${ }^{1}$}

$\mathrm{P}$ roponer la reflexión sobre el desarrollo, además de un acierto, es un aporte a los debates abiertos por la crisis. La perspectiva que ésta nos abre, en especial a partir de lo que ocurre en algunos de los países periféricos del centro, nos permite decir que poner a la justicia social en el centro de las agendas no es una opción académica más. En realidad, se trata de un cambio de orden en objetivos y prioridades que, de llevarse a cabo, sitúa a los estudios del desarrollo en el ojo del huracán de las deliberaciones políticas actuales, no sólo sobre la recuperación o el futuro del (des)orden global, sino sobre el porvenir mismo de las democracias.

Esta operación, que podríamos pretender que fuese paradigmática, lleva a una reflexión arriesgada sobre los adjetivos, opciones y restricciones que implica la reconquista de la senda del desarrollo. Reconquista que, quizá como sólo ocurrió en los inicios del pensamiento histórico sobre el cambio de las estructuras sociales y el carácter de una ciudadanía que apenas se asomaba a la configuración del poder estatal moderno, tendrá que llevarnos a concebir el desarrollo como un proceso complejo que involucra grandes y pequeños cambios sociales así como formas diversas de aprendizaje democrático.

Lo que plantea esta coyuntura impuesta por la globalidad de la crisis no sólo son las mutaciones en la conducción económica o la protección social, significativas o epidérmicas, según sea el caso. Sobre todo, lo que está en cuestión es la o las maneras en las que tanto las sociedades como sus Estados podrán sortear el actual laberinto desafiante que es posible resumir en la propuesta de que lo que estamos viviendo no sólo es una época de cambios sino todo un cambio de época, en palabras de Alicia Bárcena, secretaria ejecutiva de la Comisión Económica para América Latina y el Caribe (CEPAL).

${ }^{1}$ Una versión preliminar de este artículo fue presentada en el Primer Seminario Internacional sobre Estudios Críticos del Desarrollo. Crisis, desarrollo y trabajo, organizado por la Unidad Académica de Estudios del Desarrollo de la Universidad Autónoma de Zacatecas el 13 y 14 de febrero de 2013. 
Puesta en los márgenes de la discusión académica y política internacional, privilegiando los teoremas sobre la eficiencia de los mercados y la imperiosa necesidad de la estabilidad fiscal y financiera, de precios y cambiaria, la economía política del desarrollo puede volver por sus fueros en la medida en que la academia y los propios comandos políticos de la economía se vean impelidos a reflexionar sobre el largo plazo como condición para lidiar con la tormentas del presente. De otra forma, se asuma o no, el presente continuo del globalismo deviene ominoso estancamiento.

Por qué y cómo unas naciones fallan y otras no; por qué unas naciones se enriquecen y otras se mantienen sometidas a los círculos viciosos de la pobreza; cómo y en qué condiciones las élites gobernantes deciden buscar un giro en sus políticas y estrategias para acometer explícitamente la gran tarea del cambio social y aún político para el desarrollo; éstas son cuestiones que, entre otras, ocupan los simposios y las cumbres de la política internacional y dan voz, hasta hacerles eco, a las proclamas por otro desarrollo y el altermundismo que ahora se empata con los reclamos de la indignación juvenil y el rechazo activo a las cúpulas de Wall Street.

El globalismo se tornó sentido común al calor del gran cambio del mundo que irrumpió con la globalización de fin de siglo y el fin del régimen bipolar de la Guerra Fría. A pesar de las conmociones y turbulencias recientes, este sentido común es construido y reconstruido en y desde las esferas mediáticas y los centros de pensamiento y formación de opinión, generalmente vinculados al poder constituido o los poderes de hecho; tan sólo por este contexto y su génesis, el globalismo no se presta fácilmente a deliberar, no se diga fomentar, el surgimiento de nuevas ideas sobre el gobierno del Estado y la economía. Más bien, conforma una poderosa serie de trincheras contra esas ideas y su conversión en paradigmas alternativos; también, sirve como soporte de revisiones y renovaciones cosméticas del pensamiento y las corrientes principales, cuya reproducción no es lineal sino que se da a través de las casamatas institucionales e ideológicas donte tiene lugar el conflicto social y clasista y la confron- 
tación política permanente que es propia de las sociedades complejas. «Los cambios paradigmáticos en la economía no siempre resultan de planteamientos que perfeccionen la formulación anterior o que den una mejor explicación del comportamiento de ciertos fenómenos humanos. Invariablemente ofrecen verdades, anhelos sociales e individuales, entremezclados y sintetizados en planteamientos ideológicos atractivos» (Ibarra, 2009).

Los acontecimientos en Europa y Estados Unidos hablan de un sinuoso rumbo de confrontación ideológica y, desde luego, de lo difícil que es y será dejar atrás la crisis actual. Estas lecciones deben ser de particular interés para nosotros en la búsqueda de un cambio de rumbo que, sin soslayar las enormes mudanzas estructurales y mentales que ha traído consigo la globalización, se proponga orientar la construcción de estrategias de desarrollo renovadas y renovadoras. El reto estriba en tomar debida nota de lo existente y dilucidar seriamente su utilidad para sostener o impulsar este nuevo curso, con el fin de no reincidir en uno de los errores más dañinos en que incurrió el cambio estructural (neoliberal) globalizador: echar al niño junto con el agua sucia de la bañera.

Para darle a la globalización un sentido propio, que se corresponda con las historias y las visiones nacionales, en lugar de sofocarlas y encorsetarlas en pensamientos pretendidamente únicos, requerimos rescatar al bienestar social y a la justicia distributiva como el gran binomio donde debe incrustarse el cambio económico y las estructuras productivas que resulten de dicho cambio.

Es en esta inversión de criterios y valores, respecto de lo que ha ocurrido a lo largo de la era neoliberal, donde se pueden encontrar las claves para darle al crecimiento económico un rostro humano y a la globalización un aprovechamiento efectivamente planetario. De aquí la necesidad de modificar objetivos y criterios de evaluación, como condición para empezar a imaginar otros caminos para el desarrollo dentro del actual (des) orden mundial.

En presencia de una despolitización intencionada y sistemática de la cuestión social, promovida por la llamada revolución neoliberal, la conver- 
sación entre economía y política, entendida como mercado, Estado y democracia, no podrá enfilarse por la senda de una modernidad robusta y consistente. La sistemática separación de lo social y lo económico ha sido un proyecto de larga data que adquirió especial intensidad bajo la bandera del globalismo que llevó al mundo a la crisis. Por ello, reposicionar un desarrollo adjetivado con equidad para la igualdad y, también, como un legítimo derecho humano fundamental es urgente. Como lo es su necesaria traducción en políticas y responsabilidades estatales que, para conformar una auténtica alternativa, deberán responder con claridad a los criterios de evaluación que se deriven de la mencionada inversión en objetivos y valores.

Cuando hablamos de desarrollo y bienestar social así como de políticas de Estado, en el sentido anotado, apuntamos a la posibilidad de empezar a reconstituir el presente hacia el futuro. Esto reclama esfuerzos intelectuales y de voluntades políticas destinados a reconfigurar el entramado de las relaciones humanas, para que pueda servir de cauce racional y progresista, democrático y de equidad, a un desarrollo no sólo desde adentro sino a partir de una globalización cuya crisis material e institucional exige medidas de emergencia, a la vez que transformadoras, para asegurar la reproducción de nuestras sociedades. En esta tesitura, la idea del derecho al desarrollo se inscribe en un proyecto global mayor que bien podríamos llamar civilizatorio.

La búsqueda de un régimen económico y social planetario al servicio del «factor» humano — como lo planteara recientemente la pensadora italiana Rossana Rossanda pensando en su país - comprometido con la participación activa de sus miembros en nuevos experimentos democráticos, ha dejado de ser una utopía para ser vista como la única combinación capaz de ofrecer una salida viable a la fiebre distópica que se ha apoderado del mundo en estos años de mudanza frenética. Se trataría de una ruta capaz de ofrecer a la especie no sólo visos de supervivencia, sino horizontes de evolución sostenibles y sustentables: defensa y promoción de la cohesión social y del medio ambiente. En palabras de Adela 
Cortina: «La afirmación liberal según la cual hay individuos aislados que un buen día deciden sellar un contrato no deja de ser una hipótesis ficticia. No existen esos individuos aislados, sino personas vinculadas a los demás seres humanos, es decir, en relación política» (Arroyo, 2013).

\section{EL ESTADO EN EL DESARROLLO}

Un marco de referencia para imaginar, diseñar y evaluar sendas políticas como las sugeridas, debe partir de la economía política del desarrollo. En toda discusión sobre el desarrollo y sus perspectivas, hay una economía política y una historia nacional y mundial que no se puede desdeñar.

El desarrollo visto como un proceso de cambio social, político y económico requiere de un correcto funcionamiento de las instituciones, pero también implica una reestructuración básica de valores y actitudes. Asimismo, los bloqueos y diques estructurales para dicho cambio sólo pueden encararse, como hemos dicho, desde una plataforma activista de diseños y estrategias que rompan la estabilidad fruto de esos bloqueos, para desembocar en diferentes constelaciones institucionales capaces de dar cauce y acumular las energías desatadas por el cambio económico y social y las políticas destinadas a ello.

El desarrollo moderno, en especial el que arranca con el fin de la Segunda Guerra, pronto se desplegó en un proceso institucional y político inseparable de la aspiración a crear un régimen universal de derechos. Noción que, a su vez, remite a la de justicia integral porque si la igualdad que promete la democracia se limita a las leyes o a las urnas resulta del todo insuficiente para asegurar y extender la justicia social. Así, el desarrollo entendido como creación y expansión de derechos, los derechos como justicia y libertad; la política como acción y compromiso con el código democrático, son coordenadas imprescindibles para construir una nueva agenda. 


\section{REPASO MEMORIOSO}

La idea del desarrollo como progreso, como «estar al día», es tan vieja como la modernidad; forma parte no sólo del pensamiento clásico de las ciencias sociales, sino de la experiencia política internacional de los dos últimos siglos. Sin embargo, la preocupación por este proceso central de la modernidad sólo se volvió universal y estratégica hasta la segunda mitad del siglo $\mathrm{xx}$.

Fue en la segunda guerra cuando el mundo topó con un gran punto de inflexión, luego de la catástrofe económica de la Gran Depresión y el ascenso de los fascismos; en más de un sentido, se trató de la primera gran vivencia masiva de la globalización al poner en contacto a hombres de todas las latitudes e introducir a poblaciones enteras de las regiones atrasadas en lo que hoy llamaríamos la modernidad, condensada entonces en la organización vertical y racional de los ejércitos y la enorme capacidad de destrucción de las armas en uso. Cierto es que esto se hizo a través de la destrucción más violenta imaginable, pero sus lecciones fueron asimiladas por las élites emergentes y en formación en los territorios todavía coloniales y en América Latina, pero también, desde luego, en India y China.

Así, el derecho al desarrollo empezó a plantearse como un reclamo universal, y la autonomía de los Estados y la soberanía de las naciones como componentes indisolubles del nuevo orden. Como paradigma reinaban el pleno empleo y la protección social, que resumían la terrible experiencia del desempleo y la penuria de la Gran Depresión; su derivación obligada fue la premisa de que el crecimiento económico sostenido era la ruta por excelencia para arribar a plataformas de progreso que se concretaban en los Estados de bienestar.

La combinación de crecimiento económico alto y sostenido con redistribución social daba sentido histórico al concepto mismo de desarrollo, convertido pronto en la idea de fuerza en la posguerra y, en particular, de los nuevos mundos que emergían de la descolonización y del reclamo industrializador latinoamericano inspirado por el pensamiento de la CEPAL y Raúl Prebisch. 


\section{DE LA EUFORIA DEL GLOBALISMO}

\section{AL EXTRAVÍO DEL DESARROLLO}

Con las convulsiones del fin del siglo xx, resumidas en la implosión del comunismo soviético, la globalización de las finanzas y, en menor medida, de la producción y el comercio, sobrevino un radical cambio paradigmático. En lugar de pleno empleo y protección social, se impuso la lucha contra la inflación, la estabilidad financiera y la reducción de los compromisos del Estado con el bienestar y la justicia social. En varios países, las nociones de ajuste externo, pago de la deuda externa, así como las revisiones - y reversiones - de los Estados se volvieron criterios y políticas centrales en consonancia con lo que se llamó el Consenso de Washington.

Así, más que un desarrollo «esquivo» como el experimentado en los años setenta con sus oscilaciones, rupturas y la «estanflación», lo que el mundo empezó a vivir en las dos últimas décadas del siglo xx fue un extravío en términos de aquellos valores y criterios que dieron lugar a la gran gesta del desarrollo como derecho y cambio social.

Con su catálogo de recomendaciones destinadas a «volver a lo básico», el Consenso pretendió redefinir el perfil global del mundo y asegurar la implantación de un nuevo orden mundial. La visión de una economía de mercado irrestricta por su eficiencia sustenta la propuesta, que se pretende universal y racional, de reducir el Estado a su mínimo, hasta volverlo una entidad puramente instrumental.

Se fue tan lejos en la carrera por «corregir» lo que se tenían como excesos y adiposidades del Estado y sus tareas, en la revisión de ideas y proyectos, que incluso se pretendió desaparecer del mapa de las prioridades internacionales la idea misma del desarrollo. Con esto, el derecho al desarrollo fue sometido a las exigencias del mercado y las finanzas, interpretadas arbitrariamente desde el poder internacional. El resultado está a la vista.

De una globalización económica y financiera vista como portento, asistimos hoy a una brutal y costosa constatación: el así llamado pensamiento único, con su postulación de la eficiencia de los mercados y su 
imbatible eficacia para autorregularse, no sólo estaba equivocado en sus premisas fundamentales, sino que ha llevado a una crisis de enorme profundidad cuyos efectos son aún imprevisibles para los tejidos económicos y sociales.

El caos actual no es más que la expresión de una globalización (auto) impuesta. Si bien puede proponerse, al menos como hipótesis de trabajo, que el proceso globalizador como lo hemos conocido ha llegado a otro punto de inflexión. Las rutas a seguir son todo menos claras con una Europa amenazada en su integridad social y su unidad como proyecto, y con ello a la economía mundial, con unos Estados Unidos cuyo crecimiento apenas se asoma, su consumo se estanca y su empleo se contrae. Es en este contexto que una manera menos incierta de «estar en el mundo» radica en acudir a la historia para ser capaces de aprovechar los resquicios que la coyuntura abierta por la crisis permite.

\section{POR UN REPLANTEAMIENTO ESTRATÉGICO}

La circunstancia crítica de la situación actual debería conducir al replanteamiento de los términos de la estrategia seguida; la explosión financiera y la codicia como cultura llevan a la necesidad redescubierta de su regulación. La necesidad de contar con Estados fiscales, fuertes y dinámicos es insoslayable; sólo así se podrá intentar la delicada y siempre veleidosa combinación de crecimiento económico con equidad y estabilidad.

Si hubiera que fechar el origen de los recientes intentos de recuperación del Estado, podría proponerse que fue en 1997, cuando el Banco Mundial liderado por Joseph Stiglitz desató este empeño: «las enseñanzas de los grandes éxitos conseguidos [... desde la industrialización de algunos países en el siglo xix hasta el 'crecimiento milagroso' alcanzado en la posguerra por Asia Oriental [... ] lejos de respaldar la teoría del Estado minimalista, demuestran que el desarrollo exige la existencia de un Estado eficaz» (Banco Mundial, 1997). 
No está por demás recordar la categórica advertencia de Polanyi (1992) en su análisis del colapso de la primera fase de globalización: si el mercado pretende subordinar a la sociedad, terminará por destruir sus propios cimientos.

La civilización del siglo xıx se asentaba sobre cuatro instituciones. La primera era el sistema de equilibrio entre las grandes potencias [... ] La segunda fue el patrón-oro internacional [...] La tercera, el mercado autorregulado [...] La cuarta, en fin, fue el Estado liberal.

[... L La clave del sistema institucional del siglo xix se encuentra, pues, en las leyes que gobiernan la economía de mercado. La tesis defendida aquí es que la idea de un mercado que se regula a sí mismo era una idea puramente utópica. Una institución como ésta no podía existir de forma duradera sin aniquilar la sustancia humana y la naturaleza de la sociedad.

El papel del Estado social y generador de externalidades tecnológicas e institucionales es fundamental y no contingente para una determinada etapa de crecimiento o desarrollo. En un mundo de riesgos globales, la consigna de sustituir la política y el Estado por la economía es cada vez menos convincente. Por ello es que la nueva agenda para reformar el Estado no tiene nada que ver con un discurso de tabula rasa o un imposible regreso al pasado. Por el contrario, busca ser fruto de una recapitulación conceptual y de experiencias, de una puesta al día que, sin renunciar a la historia, ayude a emprender un nuevo curso de desarrollo, que abra cauces para un proyecto de inclusión social y de consolidación democrática.

La reforma del Estado, que la época reclama para encaminarse a un cambio fundamental, tiene que tener como eje maestro una reforma social del mismo. No puede reducirse a satisfacer demandas específicas de cambios en el uso de los recursos o la conformación institucional; para ser un componente y un catalizador de una efectiva y radical «reforma de las reformas» del Estado, debe centrarse en la reconstrucción de los tejidos y procesos sociales básicos, lo cual implica, a su vez, una redistribución del poder, un reacomodo radical de las relaciones y pesos 
entre las esferas de la economía, además de su comando en la asignación de los recursos y la distribución de los ingresos y la riqueza. También, sin duda, tanto en la esfera del poder político y administrativo como en la propia división del trabajo dentro del Estado.

\section{CAMBIO DE RUMBO}

El liberalismo, nos enseñó Bobbio, no es sinónimo del liberismo manchesteriano que pretendía reducir toda la vida social, económica y política a los criterios y mandatos de la competencia y el mercado. La historia ha dado la razón a pensadores como Stuart Mill, quienes siempre pensaron que el catecismo de Adam Smith era inseparable de sus sentimientos morales y de un papel relevante del Estado, tanto en la economía como en la política y el conjunto de la vida social de las naciones. Hipótesis que, por cierto, fueron reelaboradas a lo largo del siglo $\mathrm{xx}$ por los pensadores y promotores del socialismo liberal, de la revolución keynesiana y, luego, del Estado de bienestar que fundió en un pacto en verdad civilizatorio las inspiraciones de cristianos, católicos, liberales y socialistas democráticos, para forjar el sendero de progreso económico con equidad. A lo largo de los «treinta gloriosos» o la «edad de oro» del capitalismo, tuvo lugar una especie de gran emulsión de ideas e instituciones que desembocarían en la constitución de la Unión Europea y su mensaje de democracia, innovación e inclusión social.

Luego del final de la Guerra Fría, el gran pacto europeo parecía destinado a ser el soporte de una nueva era donde la certeza colectiva sobre una «paz eterna» kantiana se combinara con la confianza compartida en un futuro de equidad y seguridad sociales para todos. Luego sobrevino la primera crisis de la globalización y el mundo desarrollado entró en un tobogán de revisiones y reversiones en cuanto al mantenimiento y durabilidad de tales certezas y confianzas esperanzadas.

Para el mundo en desarrollo, por el contrario, se han abierto caminos posibles inspirados en la experiencia asiática, el impetuoso crecimiento chino, la modernización acelerada de Corea y el propio avance de India. 
En América Latina, en especial en el Cono Sur, se vive una era de auge en el comercio internacional de sus materias primas y para muchos observadores de lo que se trata es de poner a prueba la fortaleza y el vigor de los Estados para propiciar una efectiva redistribución de esas rentas extraordinarias y, a la vez, sembrarlas para crear los cimientos de un crecimiento futuro más diversificado y denso.

Los países centroamericanos y México, por lo contrario, han tenido que sufrir una acentuada interiorización de la crisis y la recesión estadounidense sin las suficientes capacidades instaladas para responder de manera contra cíclica o para explorar caminos alternativos de expansión. Con todo, en esta subregión septentrional de América Latina también se vive un momento de aliento y esperanza en cambios de rumbo en la dirección de procesos de maduración e integración de sus estructuras productivas, internacionalizadas abruptamente, pero tal vez en condiciones de plantearse un mejor aprovechamiento de esas aperturas en el futuro.

La crisis, en efecto, ha (re)abierto la posibilidad de plantear que, frente a la globalización entendida hasta hoy como trayecto y pensamiento único, es factible proponer la diversidad de formaciones sociales y rutas para el desarrollo. Frente a la dictadura del ajuste financiero y el equilibrio fiscal, entendido unívocamente como «déficit cero», se pueden imaginar nuevas maneras de estructurar los Estados nacionales, reestructuración que puede auspiciar nuevas combinaciones entre la apertura externa y la promoción interna que, sin renunciar al comercio exterior y a la interdependencia, ponga por delante la noción operativa pero trascendente del desarrollo humano.

Colocar lo social como punto de partida para reordenar objetivos y visiones del desarrollo, puede probarse no sólo útil para la estabilidad social, sino convertirse en una fuente de renovación de la legitimidad de la política y del Estado. Pensar la política social como componente indispensable del desarrollo democrático es empresa civilizatoria. Reasumir las dimensiones nacionales para abordar lo global, y no para exorcizarlo, es tarea central. 
El camino del mundo a una eventual globalización de la política económica parte de, se imagina y prepara en los Estados nacionales y pasa por una modulación cuidadosa de las políticas en las que se condensan las diversas y encontradas voluntades sociales. La mundialización de la política económica en consonancia con los requerimientos de una globalización reconstruida no podrá eludir el gran divorcio entre la economía y la demografía que se despliega en la escisión, convertida en parámetro de la visión neoliberal, entre la política económica y la social. Disonancias que están en el fondo de la gran división social que amenaza la cohesión fundamental de las naciones, a través de una anomia impasible y de una migración internacional convertida en la vía por excelencia para el gran ajuste subversivo del mundo desigual de nuestros días. «Volver a la normalidad va más allá de hacer que las tasas de crecimiento se recuperen y que el aparato productivo salga de su recesión. Implica que se volverá una 'normalidad' distinta» (Anguiano, 2012).

Vale la pena insistir: la equidad y la justicia social son objetivos legítimos y centrales del desarrollo; además, la experiencia reciente ofrece argumentos robustos de que son también condiciones esenciales de una estabilidad macroeconómica comprometida con el crecimiento económico, así como de la gobernabilidad democrática. La justicia social es inseparable del derecho al desarrollo. Dice Carpizo (2012:6): «La noción de justicia social no se encuentra en desuso [... [ La fuerza especial del concepto de justicia social se encuentra en que además de su significado jurídico y constitucional, se impregna de carácter sociológico y, en particular, de un sentido de equidad». Es un derecho ciudadano y su realización debería ser una prioridad para los Estados, en la crisis y más allá de ella. Por ello la necesidad de reconocer como derecho universal de los Estados y de las naciones, la capacidad de decidir las pautas de desenvolvimiento económico y distribución social, así como las formas de inscribirse en el mercado y la economía globales.

La crisis puede ser un acicate para identificar y reflexionar sobre los límites de la globalización para autorregularse; «volver a lo básico», 
consigna preferida del neoliberalismo, puede cambiar de signo y convocar a redescubrir la pertinencia y la vigencia de los Estados para crear regímenes de seguridad humana y protección del entorno. Para poder articular un sentido de futuro, es indispensable poner el desarrollo por delante y a la equidad para la igualdad en el centro.

La ruta del globalismo, entendido como la ideología al modo de la fórmula neoliberal, no puede seguir presentándose como receta única. Democracia y modernidad económica sólo serán viables en la medida que las sociedades pongan en el centro a la equidad; en donde lo social ya no sea residuo de lo económico ni referencia contingente de la política.

Democracia y mercado no son términos intercambiables [... ] si los ciudadanos no pueden intervenir en el dominio de una economía cada vez más desconectada de lo social y a la que se le niega la posibilidad de utilizar los instrumentos de política necesarios para corregir los desequilibrios que el mercado por sí mismo no puede solucionar, la sociedad civil deja de tener sentido [...]. Antes de que ello ocurra es necesario encontrar, lo más pronto posible, las alternativas sacrificadas en los altares del «pensamiento único» (Rapoport, 2002).

La pertinencia de incorporar la dimensión de los derechos para buscar modular los acomodos de la globalización, adquiere particular fuerza desde la perspectiva de la economía política de la crisis. Es desde esta atalaya que puede (re)conocerse el derecho al desarrollo como un derecho central y fundamental de la modernidad globalizada.

Así, puede aprenderse a leer productivamente las señales de un entorno mundial marcado por la incertidumbre, la desigualdad multidimensional y la pobreza masiva y planetaria, y traducirlas en el desarrollo de los derechos. La oportunidad de una inscripción de la democracia en los objetivos del desarrollo, tan integrales e integradores como sea posible, parece ser la senda más segura, aunque tal vez la más ardua, para hacer factible la ambición, revigorizada por el cambio del mundo, de avance económico con profundización democrática y equidad social. 


\section{BIBLIOGRAFÍA}

Anguiano, Eugenio (2012), Mercados financieros internacionales. Su historia, evolución y crisis, México, Universidad Nacional Autónoma de México.

Arroyo, Francesc (2013), «Competir o convivir», El País, disponible en: http:// cultura.elpais.com/cultura/2013/05/15/actualidad/1368618621_893759. html.

Banco Mundial (вм) (1997), El Estado en un mundo en transformación. Informe sobre el desarrollo mundial, Inglaterra, Oxford University Press.

Carpizo, Jorge (2012), «El estado de los derechos de la justicia social», Revista Latinoamericana de Derecho Social, núm. 14.

Ibarra, David (2009), «Oteando el futuro», Economíaunam, vol. 6, núm. 18.

Polanyi, Karl (1992), La gran transformación. Los orígenes políticos y económicos de nuestro tiempo, México, Fondo de Cultura Económica.

RAPOPORT, Mario (2002), «Orígenes y actualidad del «pensamiento único», en Julio Gambina (comp.), La globalización económico financiera. Su impacto en América Latina, Buenos Aires, Consejo Latinoamericano de Ciencias Sociales. 
